complained of hæmorrhage and leucorrhœa. When the cervix had been dilated and the polypus removed, the nature of the case was clear.

If cancer beginning within a cervical canal the lower end of which is not open enough to admit the finger is to be diagnosed early, this can only be done by dilating the cervix. If the symptoms suggest cancer, and nothing is perceived by finger and speculum to account for them, the suspicion can be confirmed or verified only by dilatation of the cervix. This done, the finger in the cervix will either feel the firm, smooth ridges of the arbor vitæ, or there will be at some part of the canal a nodule, a warty growth, or a ragged ulcer.

The remarks I have made as to the liability to error of conclusions based on the microscopical examination of broken off bits apply to this form of cancer more strongly than to cancer of the vaginal portion. If we scrape off bits it is not possible to be sure where they come from. There may be cancer at one part of the canal, and a villous erosion, or an ordinary mucous polypus at another. But this form of cancer advances so fast, and its initial symptoms are so slight, that it is seldom we have the opportunity of diagnosing and treating it early.

\section{A NOTE ON AUDITORY VERTIGO.}

By Sir WILliaM B. DALBY, M.B., F.R.C.S., Consulting Aural Surgeon to St. George's Hospital.

IF I venture to say that Dr. Stephen Mackenzie's paper on "Aural Vertigo" in the British Medical Jodrnal of May 5 th covers the whole area (so far as it has been usefully occupied) of previous observers, whilst it gives his own valuable suggestions, I am sure that he will acquit me of any attempt to pay him a compliment. Both he and the readers of the JoURNAL will perhaps, in consideration of the interest which I take in the subject, permit me to offer a few remarks upon his arrangement of the subject and upon some of his observations.

In studying this subject, what we all want and what we must have, if our knowledge of it is to advance or become in any sense accurate, is a determined line of division in these cases. On one side of this line must be placed those cases in which the external and middle ear are healthy. On the other side of the line those cases in which one or both of these two divisions of the ear are unhealthy. Until this is done there will remain, as there now is, endless confusion. The next point is that the term "Ménière's disease" must either be dismissed (it always was indefinite), or, if it is to be retained, it must be clearly understood that it can be only applied to those cases in which there is no disease of the conducting media, and then only used to express a certain train of symptoms, which, beginning by vertigo, nausea, sweating, perhaps vomiting, tinnitus, and deafness on one side, continues by permanent deafness, a long, lasting, and varying tinnitus, a gradual subsidence in frequency, and severity of vertigo and unsteadiness of gait. The very words of Dr. Mackenzie-"In the great majority of cases, in my experience, some disease is found in the middle ear"-show the necessity of this division and exclusion. My own experience not only accords with his remark, but it has become to me an ordinary and daily matter to regard in middle-ear disease vertigo as so common a symptom that it ranks amongst other symptoms, such as pain, deafness, and tinnitus, although it is not so prominent. It is also true that at one time it is of no great importance, whilst at another it is a symptom of the gravest significance. Thus, when it accompanies long-continued and profuse discharge from a perforate membrane, it often marks the advent of cerebral complications. In the course of many affections of the middle ear it is not of great consequence.

Let, then, all cases where the external and middle ear are involved be put on one side in considering the pathology and treatment of aural vertigo. Also let some others be put aside, such as those where the intelligence of the physician at once detects the state of affairs, as when Dr. Mackenzie writes: "I think one of the most practical points in warding off attacks is to keep your finger on the pulse-if one may use the expression-that is, to watch and keep down arterial tension. A dose of cabomel, taken in such circumstances, patients have assured me, has averted attacks which they be- lieve would otherwise have occurred." I shrewdly suspect that Dr. Mackenzie has occasionally, with a very full knowledge of the possible danger, averted an attack of apoplexy. I am reminded at the moment of a man, aged about 60 , who, having no disease of his external or middle ear, used to become at times almost completely deaf, with furious tinnitus and considerable vertigo. By my advice he took a strong purge in the shape of calomel and colocynth pills when he had such attacks, and twenty-four hours after always recovered his hearing. The order of events-deafness, pills, and recovery-occurred six or seven times a year for three years, and after then no recovery. I can recall many instances resembling this. The number of persons with obvious arterial tension, consequent vertigo, tinnitus, and deafness that $I$ have placed under physicians is very large indeed. They have not only been relieved by treatment and diet, but, later on, I have known several to illustrate the cause of these symptoms by dying of apoplexy. It is, therefore, also necessary to severely put aside these cases of arterial tension and atheroma as well as the middle-ear cases if we are to get at the root of true auditory vertigo-the vertigo which does not shorten life by a day. We shall then, so to speak start fair. Persons who suffer from vertigo arising from all sorts of causes are very naturally alarmed, and at the present time they seem to find consolation in the term "Ménière's disease," which they glibly announce they suffer from, so that I cannot but think that this state of things must arise from a somewhat too loose application of a term which, I submit, so far as its accurate pathology is concerned, is almost meaningless.

Under these circumstances, I think the most we can do for it, and possibly the least, will be by common consent to insist upon its being confined to the class of cases I have indicated. All the theories which have been held by various observers at various times have been enumerated by $\mathrm{Dr}$. Mackenzie, and the very variety of theories shows how uncertain is the exact state of the lesion. My own views are referred to by Dr. Mackenzie, so I need not repeat them.

\section{ON CROUPOUS PNEUMONIA IN LONDON DURING 1893.}

Br W. P. HERRINGHAM, M.D., F.R.C.P., Medical Registrar to St. Bartholomew's Hospital; Physician to the Children's Hospital, Paddington Green.

The past year, 1893, was remarkable for the very large number of cases of croupous pneumonia. Wishing to see whether any explanation could be found for this, I tabulated the cases admitted at St. Bartholomew's. The results were so striking that I thought it worth while to test them by larger numbers. I therefore applied to the physicians of Guy's, of the London, and of St. Thomas's Hospitals, who were kind enough to allow me to use their records to the extent required for my purpose. To them, to the physicians of St. Bartholomew's, and to the Registrars, Dr. Box, of St. Thomas's, Dr. Bryant, of Guy's, and Dr. Schorstein, of the London, who have been most courteous in assisting me, I am glad to return my hearty thanks.

I need not discuss in detail the etiology of croupous pneumonia. My purpose was to discover whether its prevalence varied with atmospheric conditions; but whether these are predisposing or exciting causes, and whether they act by weakening men, or by strengthening microbes, are questions beyond the scope of my inquiry.

I will first explain my tables, and then point out what they prove.

I have taken all cases of acute croupous pneumonia admitted during 1893 to the above four great hospitals, except inpatients under 5 years of age. These I have omitted owing to the great difficulty of diagnosis at that age between croupous and catarrhal pneumonia. The cases so obtained, 922 in number, I have divided into fortnightly periods, according to the date of admission. The numbers are not large enough to allow of weekly periods, for such statistics as these are but rough guides after all, and if numbers are small, are not only useless but misleading. The date of onset would have been better than the date of admission, but I could not, 
for various reasons, obtain this in every case, and preferred to make the tables uniform rather than select. The disease is so short that the fallacy of this method is not great.

I have copied the atmospheric conditions from the weekly returns of the Registrar-General. I have chosen the temperature of the air, the weekly mean of its highest and of its lowest points, and of the range between the two, the relative humidity (relative, that is, to the temperature), and the direction and strength of the wind as the conditions most likely to have an influence upon the prevalence of pneumonia. The almost uninterrupted sunshine, and the extremely small rainfall from the middle of March until August which rendered last year so exceptional will be in the memory of all.

I have not appended the mortality rate of these cases; the numbers are too small to be of any value.

The tables show that the year may be roughly divided into four periods. The first, from January 1st to March 25th, during which the average number of pneumonia cases was just over 30 in the fortnight; the second, which I will call the pneumonia season, comprising April, May, and June, during which the average was 62 ; the third from July 1st to October 2lst, during which it was $27 \frac{1}{2}$; and the remaining ten weeks, during which it was 16

I had better at once point out that these propertions do not agree with the Registrar-General's tables of mortality for London. This is partly due to the inclusion of bronchopneumonia in these tables. But if all the cases under 5 years old be subtracted, which eliminates nearly all the bronchopneumonia, the numbers are still not parallel. The mortality tables show the "pneumonia season" quite distinctly, but the deaths in January, November, and December are very much higher than in February and March, or than in the period from July to October. This may perhaps be due to the fact that the hospitals treat the poor only, and that cold weather affects the rich, whose houses are hotter, more than the poor. But the term pneumonia covers a multitude of diseases, and I think this is the chief cause of the discrepancy. Hospital cases are very much more accurately diagnosed and named than others, and I have no hesitation in saying that when their records and those of the RegistrarGeneral conflict, the latter are wrong.

The great feature in the table printed with this paper is the "pneumonia season" from the end of March to the end of June. What changes in the atmosphere coincide with it? It has evidently nothing to do with the highest points, for these rise steadily from the very beginning of the year to August, and the pneumonia season is neither at the one end of the scale nor at the other. The same may be said of the lowest points. These rise almost as steadily, and though there is a drop for the last week of March and the first in April, this is not continued through the pneumonia season. But if we look at the next column showing the daily range of temperature, a very marked difference is seen to occur just when the pneumonia season begins, and to continue through out it. Up to March 18th there is not a single week in which the average daily range is as much as $20^{\circ} \mathrm{F}$. The average is $11.1^{\circ} \mathrm{F}$. From March 25 th to July 8 th there is not a single week in which the range is not over $20^{\circ} \mathrm{F}$. The average is $23.4^{\circ} \mathrm{F}$. During the next four weeks the range is never over $20^{\circ} \mathrm{F}$, and the average is $17.1^{\circ} \mathrm{F}$. Thus the pneumonia season is seen to be just within a period during which there is a far higher range of daily temperature than the periods on either side of it can show, a period, in other words, of much greater exposure to sudden variations of heat and cold than can be found, except for a week or two at a time throughout the whole of the rest of the year. I shall refer to the two exceptions-in August and September-further on Moreover this increase of daily range begins and ends as abruptly as the pneumonia season itself.

Next it will be seen that this was a time of low relative humidity. There was very little dampness in the air. The change does not begin so suddenly as the range of temperature, but it ends as abruptly, and is quite as marked. The average degree of humidity up to March 18th was 85, the average from then till July 8th was only 66 , the average for the next four weeks was 75 . When it is considered how very slight the variations of humidity are, for the extremes are only 34 degrees of the scale apart (91 for the last week in
January, and 57 for the second in May), the dryness of the pneumonia season appears a very remarkable thing.

Next the pneumonia season is almost exactly coincident with the east winds. Up to March 18th the wind was in the east once only, from then to July 8th there was east wind every single week except three, and in one of these the wind was north, which is next door. During the whole of the rest of the year there are only four weeks in which the wind was easterly. But the east winds were not strong. The horizontal movement, deduced from Robinson's anemometer, shows the very reverse, a sudden transition from the rather windy weather which had prevailed up to March 18th to a period of light breeze. The sunshine and the drought were almost unprecedented.

Three conditions, then, coincide with the pneumonia season, a wide range of daily temperature, a dry air, and easterly wind. But "coincide" is not quite right, for they overlap the pneumonia season by a week at each end. If they cause pneumonia it is of course natural that they should precede it. But I see no explanation for their lasting beyond it. I daresay that if I were to divide up the fortnight ending July 15th into its two weeks, I might find a greater incidence of pneumonia during the first week when these three conditions were present than during the second when they were absent; but I should not believe the results if I did, and I therefore refrain. The broad facts are too striking not to have a meaning; the pneumonia season must have been connected with the atmospheric conditions which I have mentioned, and this apparent difficulty is not great enough to overthrow the conclusion.

I do not think that any further inferences can safely be drawn. The little prevalence of pneumonia during November and December is indeed coincident with a very low daily range (the average from October 22 nd to December 30 th is only $14^{\circ} \mathrm{F}$., the pneumonia incidence 16 per fortnight), but the range was lower still in the first eleven weeks of the year when the pneumonia rate was nearly double. It is, however, allowable to point out that two other periods of wide daily range of temperature, August 6 th to $26 \mathrm{th}$ (average $24.2^{\circ} \mathrm{F}$.) and September 3 rd to 16 th (average $23.1^{\circ} \mathrm{F}$.) do not, at any rate disprove the conclusion drawn from the much longer period, for each of these short times is accompanied by a pneumonia rate slightly, yet distinctly, above that of the neighbouring weeks. Neither east wind nor dryness of the air seems to have had anything to do with these times of slight increase.

Of these three conditions it seems reasonable to suppose that the wide daily range, the "hectic" temperature (I have not the gift of tongues, the scientific idioglossia, or I would invent a much longer word for the occasion) was the most effectual. Very likely dryness of the air, by aiding evaporaion, increased the influence of the first. Probably the influence of the wind, apart from any great horizontal movement, can be resolved into these two.

Lastly, it remains to compare these statistics with others. There are many tables extant embracing periods of several years in various parts of Europe. References will be found to most of them in Sturges and Coupland's exhaustive work on Pneumonia. Almost all the compilers come to the conclusion that the spring months are those in which there is most pneumonia. Thus Brunner ${ }^{1}$ whom I quote as a type, finds that most cases occur from March to May; that next in order comes the quarter December to February; and that the smallest number occur from September to November. $\mathbf{M y}$ tables are therefore supported by many previous statistics.

The inferences which $I$ have drawn are also supported by many previous opinions. Sturges and Coupland themselves came to the same conclusion; they quote others to the same effect, and Osler, writing since the publication of their book, says the same thing: "It seems that the sudden changes characteristic of March, April, and May are the important climatic factors which predispose to pneumonia."

But these general averages taken from several years are necessarily inaccurate. The month of June in one year is probably very different from the next June or the preceding. Therefore no satisfactory conclusions as to weather influence can be drawn from them. It is only by collecting a large 1 D. Archiv. f. klin. Med., xlviii, 1891. 
number of cases within a limited time in a small area that the influence of weather can be tested. This is what $I$ have done. So far as I know, it is the first attempt of the kind in Europe.

In New York, Seibert, by means of a collective investigation, has carried out a similar inquiry. He took the year March, 1884, to March, 1885, and collected over 700 cases. He found February and March to be the most pneumonic months in the year, and concluded that the three chief climatic factors were $(a)$ a low and sinking temperature, $(b)$ a high and rising humidity, $(c)$ a strong wind, and brings pneumonia into line with bronchitis. None of these conclusions are borne out by my tables; they certainly do not harmonise with European statistics and opinions, and, judging from Osler's sentence above quoted, they do not agree much better with those of America. The tables are not given in detail, so that it is impossible to compare them with my own.

Of course I do not suppose that in atmospheric conditions we shall find all the factors that cause pneumonia. Even leaving aside the pneumococcus, the weather does not explain epidemics, and it probably does not act similarly in all climates. Still, it is undoubtedly the general opinion that it has a considerable influence, and it will therefore be useful to have shown with some accuracy the conditions which last year in London varied with the prevalence of the disease.

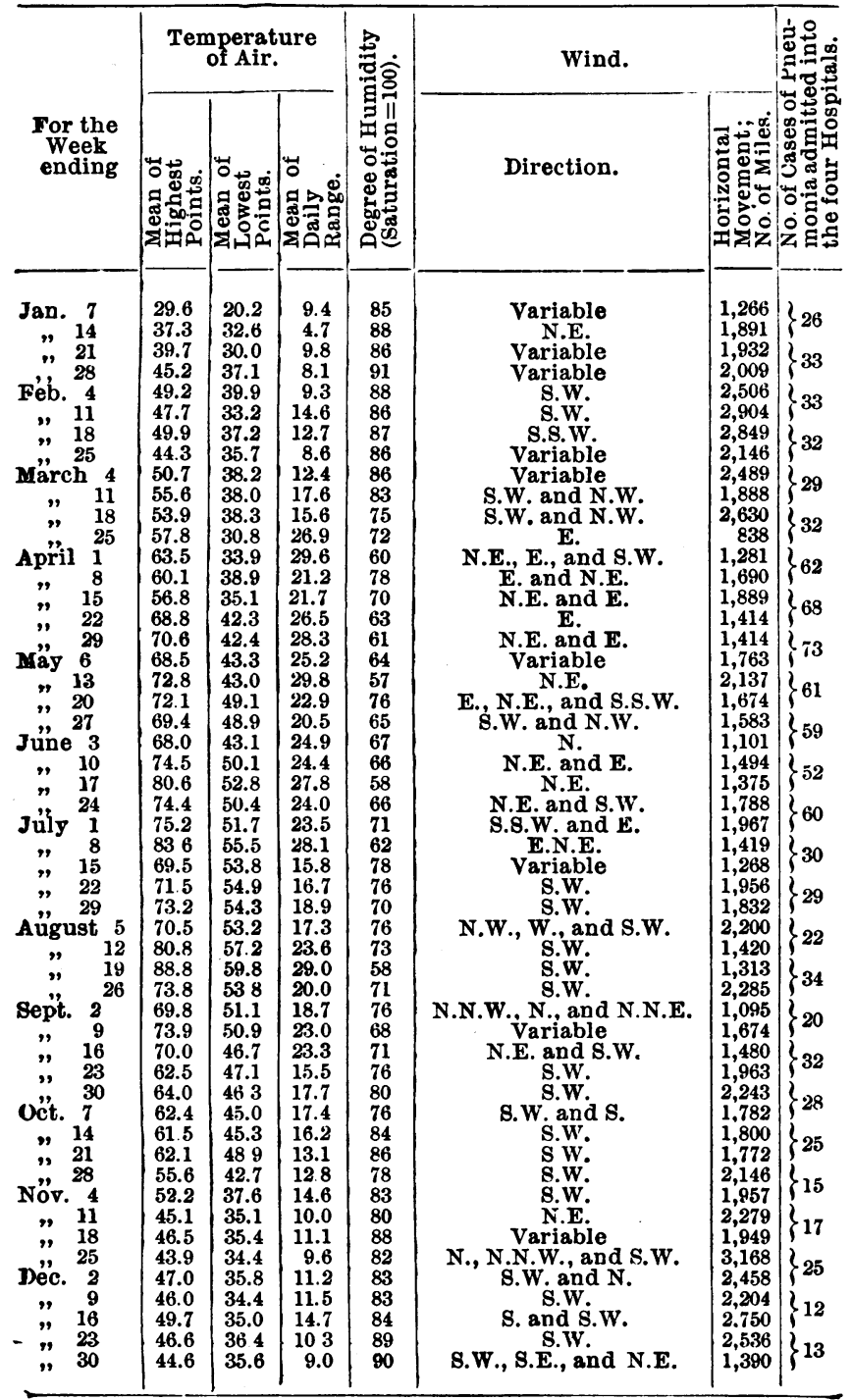

\section{A CASE OF PERFORATION OF A CHRONIC ULCER OF THE DUODENUM SUCCESSFULLY TREATED BY EXCISION.}

DEATH TWO MONTHS LATER FROM ACUTE INTESTINAL OBSTRUCTION BY A BAND.

By HENRY PERCY DEAN, M.S., B.Sc.LoNd., F.R.C.S., Assistant Surgeon to the London Hospital; Surgeon to North-Eastern Hospital for Children.

E. F., a married woman, aged 27 years, was admitted into one of the surgical wards of the London Hospital on the evening of February 17th, 1894. She was seen by me about 1.30 A.M. on the following morning, that is, a few hours after her admission, and I found her in the following condition :

Intense pain was complained of over the whole of the abdomen, perhaps slightly more marked in the epigastric regions. The patient felt very ill,, and her expression was exceedingly anxious. Vomiting occurred every few minutes, and much exhausted the patient. The pulse was 120 , feeble and regular. The respirations were rapid and irregular both in force and rhythm. The tongue was slightly furred, and very dry. There was uniform tenderness over the whole abdomen, the distension was moderate in degree, and the resonance of the percussion note was markedly increased. The temperature was $1006^{\circ}$.

On questioning the patient it was found that for about fortnight she had suffered from pain in the chest and pit of stomach, and that her doctor had been treating her for indigestion. The patient had been sick several times during the week previous to her admission, and her bowels had not been opened for seven or eight days. About twenty-four hours before admission to the hospital the patient suddenly became much worse, feeling a severe pain in the pit of the stomach, and a sensation of intense weakness. This was soon followed by vomit ng, repeated at frequent intervals.

It secmed to me pretiy evident that the patient was suffering from acute general peritonitis. The possibility of perforation of the stomach or duodenum was considered, but on. the whole I was rather inclined to think that it was a case of mechanical obstruction with general peritonitis. It was decided to operate at once. The patient was taken to the operating theatre, anæsthetised with chloroform, and an incision about 3 inches long was made immediately below the umbilicus. On opening the peritoneal cavity a quantity of purulent fluid escaped, and coils of intestine, somewhat distended, intensely congested, and covered in places with flakes of lymph, protruded through the wound. No evidence of any mechanical obstruction could be obtained, so $I$ increased the incision upwards to the ensiform cartilage, and in a few minutes I found some flakes of lymph in the region. of the gall bladder. In the centre of one of these flakes I noticed come gas bubbles, forming a kind of froth. On inserting a probe into the froth $I$ found that it passed into a cavity, which on further examination was found to be the duodenum, the perforation being situated on the anterior aspect about $\frac{3}{4}$ inch beyond the pylorus. Around the perforation a distinct induration could be felt. By means of scissors this indurated area was excised. The portion removed was elliptical in shape, measuring $1 \frac{1}{4}$ inch in its long axis, which was parallel with the transverse axis of the gut. The portion excised was found to include the ulcer and a margin of healthy mucous membrane. In the centre of the ulcer was a perforation about $2 \mathrm{~mm}$. in diameter. The floor of the ulcer was white, and the edge of the ulcer was bounded by apparently healthy mucous membrane. The elliptical opening thus made into the duodenum was sewn up by silk sutures according to Lembert's method. The peritoneal cavity was washed out with warm weak boracic lotion, well sponged, and the wound sewn up by stitches passing throughm the whole thickness of the abdominal wound. The operation lasted fifty minutes.

After the operation the patient was allowed nothing by the mouth. She was fed solely per rectum by nutrient enemata and suppositories for seventeen days. To allay thirst, 2 ounces of warm water were occasionally injected into the 